\title{
ANALISIS EFEKTIFITAS METODE PENERAPAN SNI ISO 9712:2014 UNTUK PERPANJANGAN MASA PEMBERLAKUAN SERTIFIKASI PERSONIL UJI TAK RUSAK RADIOGRAFI LEVEL 1 DAN LEVEL 2 PADA LEMBAGA SERTIFIKASI PERSON BATAN
}

\author{
Analysis of The Effectiveness Methods for Indonesian National Standard ISO \\ 9712:2014 to Extension Review of Personnel Certification the Level 1 and Level 2 \\ Radiographic Non-Destructive Testing Certification in Personnel Certification \\ Institutions
}

\author{
Widjanarko' dan Khusnul Khotimah² \\ 1,2 Unit Pusat Standardiasasi dan Mutu Nuklir, Gedung 71 Lantai 1 Kawasan Puspitek, Setu, Tangerang Selatan \\ E-mail: wied@batan.go.id
}

\begin{abstract}
Abstrak
Lembaga Sertifikasi Person (LSP) BATAN memiliki wewenang melakukan penilaian kompetensi personal Bidang Uji Tak Rusak (UTR) berdasarkan pada pemenuhan standar SNI ISO 9712: 2014 tentang Uji Tak Rusak Kualifikasi dan Sertifikasi Personal Radiografi. Masa berlaku sertifikat personil UTR radiografi adalah 5 tahun, dimana sertifikat dapat diperpanjang masa berlakunya oleh LSP BATAN untuk periode baru setelahnya. Selama ini, penerapan perpanjangan sertifikasi tersebut dilakukan dengan verifikasi dokumen terhadap aktifitas kerja. Kondisi demikian belum efektif karena tidak meyakinkan bahwa pemegang sertifikat telah melakukan aktivitas kerja berkelanjutan tanpa jeda waktu dan terpelihara kompetensinya, serta formatnya belum dapat merangkum semua kegiatan yang dilakukan oleh pemegang sertifikasi. Oleh karena itu, penelitian ini bertujuan untuk meningkatkan keefektifan penerapan SNI ISO 9712:2014 pada UTR radiografi BATAN dengan tambahan metode validasi aktivitas kerja berkelanjutan tanpa jeda waktu tidak bekerja melalui validasi wawancara secara kualitatif dengan teknik wawancara pada 9 informan dari industri pengguna radiografi. Hasil dari penelitian ini menunjukkan bahwa validasi melalui wawancara yang mengacu pada pedoman mutu LSP BATAN dengan 7 parameter validasi (2 parameter utama dan 4 parameter pendukung) mewajibkan nilai parameter utama dan total gabungannya di atas rata-rata 70 untuk sertifikasi perpanjangan berlaku pada informan 3,4, 7 dan 8, serta rekomendasi untuk dilakukan sertifikasi ulang jika nilainya dibawah rata-rata 70 terjadi pada informan 1,2,5,6, dan 9. Dengan demikian, metode validasi wawancara menjadi penilaian yang efektif untuk pemastian aktivitas kerja berkelanjutan tanpa jeda waktu dan kompetensinya terjaga bagi pekerja radiografi dalam memperpanjang masa pemberlakuan sertifikasi.
\end{abstract}

Kata kunci: Efektifitas, Metode Validasi, Perpanjangan Sertifikasi Personil, Standar Nasional Indonesia (SNI)

\begin{abstract}
BATAN's Personnel Certification Institute (LSP) has the authority to conduct personal competency assessment Non-destructive Testing (UTR) based on the fulfillment of SNI ISO 9712: 2014 standards concerning NonDestructive Testing-Personal Radio graphic Qualification and Certification. Therefore, this study aims to increase the effectiveness of SNI ISO 9712: 2014 on UTR radiography BATAN with the validation method of continuous work activities without time lag without working through qualitative interview validation by interviewing 9 informants from the users. The results of this study indicate that the validation through interviews that refer to the BATAN LSP quality guidelines with 7 validation parameters (2 main parameters and 4 supporting parameters) requires that the main parameter values and their combined total be above an average of 70 for extended certification as in informant 3 , 4,7 and 8 , as well as recommendations for re-certification if the score is below the average of 70 as happened to informants 1,2,5,6, and 9. Thus, the interview validation method becomes an effective assessment to ensure continuous work activities without interruption time and competence is maintained for radiography workers in extending the validity period of the certification.
\end{abstract}

Keywords: Effectiveness, Validation Methods, Extension of Personnel Certification, Indonesian National Standard (SNI) 


\section{PENDAHULUAN}

Sertifikasi person menjadi elemen penting dan kredensial bagi suatu industri agar dapat diakui eksistensi kompetensi tenaga kerjanya sudah handal dan memadai dibidangnya serta mampu bersaing secara global dan internasional. Sebagai respon terhadap kebutuhan yang berkembang tersebut, maka terdapat Standar Nasional Indonesia (SNI) ISO 9712:2014 Uji Tak Rusak-Kualifikasi dan Sertifikasi Personil UTR yang merupakan adopsi identik dari ISO 9712:2012, Non-destructive testing-Qualification of NDT personnel, dengan metode terjemahan dan merupakan revisi dari SNI ISO 9712:2008, digunakan untuk sertifikasi kompetensi person dalam lingkup pekerjaan atau profesi yang berbeda dengan tujuan untuk penyelarasan berbagai prosedur kegiatan sertifikasi (BSN, 2012) . Dalam rangka untuk memberikan kepastian kompetensi person tersebut, Badan Tenaga Nuklir Nasional (BATAN) melalui salah satu unit kerjanya yaitu Pusat Standardisasi dan Mutu Nuklir (PSMN) yang memiliki tugas dan fungsi sebagai unit kerja yang melakukan kegiatan sertifikasi person bidang ketenaganukliran, membentuk lembaga sertifikasi person bidang uji tak rusak yang disebut dengan Lembaga Sertifikasi Person (LSP-BATAN) (BATAN, L, 2020).

Dalam pengoperasiannya LSP-BATAN memenuhi persyaratan yang telah ditetapkan baik secara nasional seperti yang ditetapkan pada peraturan perundang undangan, dan standar nasional Indonesia, maupun secara internasional seperti yang ditetapkan pada standar internasional dan diakreditasi oleh Komite Akreditasi Nasional (KAN). Hal ini bertujuan agar sertifikasi person yang diterbitkan oleh LSPBATAN kepada tenaga kerja kita dapat diakui dan diterima baik ditingkat nasional maupun internasional. Adapun pelanggan LSP-BATAN mencakup semua industri yang memiliki pekerja pemegang sertifikasi radiografi Uji Tak Rusak.LSP-BATAN dalam melaksanakan kegiatan sertifikasi person, bertanggung jawab dan memelihara kewenangannya terhadap semua keputusan sertifikasinya, dan tidak mendelegasikan hasil keputusan sertifikasinya, seperti pada proses sertifikasi ulang, perpanjangan, penundaan atau pencabutan sertifikasi (Sutanto, 2018). Dalam menerapkan SNI ISO 9712:2014, untuk perpanjangan masa pemberlakuan sertifikasi, terdapat definisi jeda waktu tidak bekerja yang mengacu kepada klausul 3.27 SNI ISO 9712:2014 dan sebelum periode pertama validitas habis dan setiap 10 tahun sesudahnya, maka sertifikasi dapat diperpanjang oleh Lembaga sertifikasi untuk periode baru lima tahun, dengan menyerahkan bukti dokumenter pemenuhan aktivitas kerja tanpa jeda waktu tidak bekerja dalam metode UTR radiografi (BATAN, L, 2020)

Efektifitas menjadi kunci terlaksananya setiap penggunaan Uji Tak Rusak (UTR) yang bertumpu pada kesesuaian kompetensi personil yang bekerja dan bertanggungjawab dalam proses pengujian, termasuk salah satunya dalam proses sertifikasi perpanjangan (BSN, 2014). Peningkatan efektifitas penerapan SNI ISO 9712:2014 pada UTR radiografi BATAN khususnya dalam hal proses sertifikasi perpanjangan adalah sangat penting melalui pengumpulan dokumen laporan aktivitas kerja personil UTR selama 5 tahun tanpa jeda waktu tidak bekerja sebelum masa validitas habis. Pengamatan terhadap laporan tersebut dimaksudkan untuk mengidentifikasi kompetensi personil selama 5 tehun masih terjaga dan terpelihara. Jika laporan aktivitas yang disampaikan kondisinya tanpa jeda waktu tidak bekerja dari personil, maka kompetensi personilnya masih terjaga dan terpelihara, namun jika dalam laporan aktivitas kondisinya ada jeda waktu yang melebihi dari batas yang ditetapkan maka kompetensi personil terebut sudah tidak terjaga dan terpelihara (BSN, 2014).

Selama ini Bidang Pengembangan Standar (BPS) LSP BATAN hanya menerapkan persyaratan perpanjangan masa berlakunya sertifikat melalui verifikasi dokumen laporan aktivitas kerja personil UTR selama 5 tahun tanpa jeda waktu tidak bekerja, berupa dokumen secara tertulis saja yang dikirimkan oleh personil perpanjangan sertifikasi, tanpa bukti rekaman wawancara lisan terhadap dokumen aktivitas kerja berkelanjutan yang memuaskan tanpa jeda waktu tidak bekerja kepada penjamin mutu LSP BATAN. Metode ini belum efektif untuk meyakinkan bahwa personil telah melakukan aktivitas kerja berkelanjutan tanpa jeda waktu dan sulit untuk memastikan kebenaran bahwa personil tersebut telah bekerja tanpa jeda waktu dan kompetensinya terjaga karena format laporan aktivitas kerja yang belum dapat merangkum semua kegiatan yang dilakukan oleh personil perpanjangan sertifikasi.

Oleh karenanya, peranan penjamin mutu LSP BATAN dibawah Bidang Jaminan Mutu (BJM) yang bertugas melakukan verifikasi dan memutuskan hasil kegiatan evaluasi verifikasi dokumen yang dilakukan oleh BPS terhadap personil sebagai calon kandidat yang akan melakukan perpanjangan, dengan menambahkan metode yang efektif agar memenuhi keyakinan dan keberterimaan persyaratan perpanjangan sertifikasi UTR. Salah satunya melalui metode validasi wawancara untuk memastikan kebenaran 
bahwa personil tersebut telah bekerja tanpa jeda waktu dan kompetensinya terjaga. Karenanya melalui penelitian ini diharapkan dapat mengembangkan peningkatan penerapan SNI ISO 9712:2014 pada UTR radiografi BATAN dengan menambahkan metode validasi wawancara agar tingkat efektifitasnya tercapai dibandingkan hanya dengan verifikasi dokumen saja untuk perpanjangan masa pemberlakuan sertifikasi Uji Tak Rusak radiografi pada Lembaga Sertifikasi Person (LSP) BATAN.

\section{TINJAUAN PUSTAKA}

\section{a. Uji Tak Rusak (NDT)}

Non Destruction Test atau Uji Tak Rusak adalah suatu metode yang digunakan untuk menguji kualitas suatu bahan yang biasa digunakan banyak di industri. Pada dasarnya, uji ini dilakukan untuk menjamin bahwa material yang kita gunakan memiliki mutu yang baik sesuai dengan standar yang berlaku. NDT ini dijadikan sebagai bagian dari kendali mutu komponen dalam proses produksi terutama untuk indusri fabrikasi (BATAN, L, 2020)

Dalam apikasinya, NDT menggunakan bermacam-macam metode yang sekarang ini terus berkembang dengan pesat untuk memperoleh cara yang lebih baik. Ada beberapa metode dalam Non Destructive Testing antara lain, Visual Inspection (VT), Liquid Penetrant Test $(P T)$, Magnetic Particle Inspection (MT), Eddy Current Test atau Electromagnetic Test (ET), Ultrasonic Inspection (UT), Radiographic Inspection (RT), Accoustic Emissin Testing (AE) dan Leak Test (LT) (BATAN, L, 2020).

\section{b. Radiografi Industri}

Radiografi industri adalah modalitas pengujian non-destructive yang menggunakan radiasi pengion untuk memeriksa bahan dan komponen dengan tujuan menemukan dan mengukur cacat dan degradasi sifat material yang akan menyebabkan kegagalan struktur teknik (Crane, 2018). Radiasi pengion memainkan peran penting dalam sains dan teknologi yang dibutuhkan untuk memastikan kualitas dan keandalan produk (BAPETEN, 2014). Radiografi Industri menggunakan sinar- $\mathrm{X}$, yang dihasilkan dengan generator sinar- $X$, atau sinar gamma yang dihasilkan oleh radioaktivitas alami dari sumber radionuklida terbungkus (Soembogo, 2016) (BAPETEN, 2013). Setelah melintasi spesimen, foton ditangkap oleh detektor, seperti film perak halida, pelat fosfor atau detektor panel datar. Pemeriksaan dapat dilakukan dalam 2D statis (disebut radiografi), dalam 2D waktu nyata, (fluoroskopi ) atau dalam 3D setelah rekonstruksi gambar (Computed Tomography atau CT). Dimungkinkan juga untuk melakukan tomografi hampir secara real time (4-Dimensinal Computed Tomography atau 4DCT) (Podgorsak, 2005). Detektor CdTe juga dapat digunakan untuk menganalisis spektrum sinar- $X$. Teknik khusus seperti fluoresensi sinar-X (XRF), difraktometri sinar-X (XRD), dan beberapa teknik lainnya melengkapi rangkaian alat yang dapat digunakan dalam radiografi industri (Rahman, 2012).

\section{c. Sertifikasi Uji Radiografi}

Sertifikasi person adalah salah satu cara untuk memberikan jaminan bahwa personel yang disertifikasi memenuhi persyaratan skema sertifikasi. Keyakinan terhadap setiap skema sertifikasi person dicapai melalui suatu proses asesmen dan re-asesmen berkala yang diakui secara global terhadap kompetensi person yang disertifikasi. KAN memberikan akreditasi untuk untuk Lembaga Sertifikasi Person (selanjutnya disebut LSP). Lembaga Sertifikasi Person dapat memenuhi persyaratan dalam SNI ISO/IEC 17024:2012 'Penilaian kesesuaian - Persyaratan untuk lembaga sertifikasi person' yang merupakan adopsi identik dari ISO/IEC 17024:2012 'Conformity assessment Requirements for bodies certifying person' (KAN, 2020). Tujuan keseluruhan dari sertifikasi person adalah untuk memberikan kepercayaan kepada seluruh pihak yang berkepentingan bahwa personil telah memenuhi persyaratan yang ditentukan sesuai kompetensinya. Nilai sertifikasi adalah tingkat keyakinan dan kepercayaan yang diberikan oleh Lembaga Sertifikasi Person dengan menunjukkan ketidakberpihakan dan kompeten terhadap pemenuhan persyaratan tertentu (Munawar, 2018).

LSP BATAN telah memperoleh Akreditasi SNI ISO/IEC 17024 dari Komite Akreditasi Nasional (KAN) dengan Nomor: LSP-010-IDN BATAN. Dengan diraihnya akreditasi SNI ISO/IEC 17024, semakin mempertegas komitmen LSP BATAN untuk menyelenggarakan kegiatan sertifikasi person secara profesional serta dapat memberikan manfaat kepada para stakeholder. Ruang lingkup jasa sertifikasi personil LSP BATAN adalah sertifikasi Radiografi Level 1, Level 2, Level 3, Petugas Iradiator, supervisor iradiator, petugas dan supervisor proses radio isotop dan senyawa bertanda, dan petugas AAN.

Skema sertifikasi dan proses sertifikasi LSP BATAN mengacu pada SNI ISO/IEC 17024:2012 dengan standar teknis yang diacu adalah (BATAN, L, 2020). 
a) SNI ISO 9712:2015 tentang Kualifikasi dan sertifikasi personil UTR,

b) SB 002-BATAN tentang Kualifikasi dan sertifikasi petugas dan supervisor irradiator,

c) SB-010-BATAN tentang Kualifikasi dan sertifikasi petugas dan supervisor proses radioisotop dan senyawa bertanda,

d) SB-007-BATAN entang Kualifikasi dan sertifikasi petugas analisis aktivasi neutron

LSP-BATAN memiliki,mendokumentasikan dan menerapkan skema sertifikasi UTR (RT 1, RT 2, RT 3) dan ATN, dan ditinjau dalam waktu sekurang-kurangnya 1 (satu) tahun sekali, dalam rangka validasi dan perbaikan berkelanjutan. Skema sertifikasi LSP-BATAN memuat unsurunsur seperti: unsur lingkup sertifikasi, pemenuhan persyaratan pelatihan, pengalaman pekerjaan dan uraian tugas, kompetensi yang disyaratkan, kemampuan (ketajaman penglihatan) (Kumaraningrum, 2019). Skema sertifikasi LSP-BATAN mencakup proses sertifikasi yaitu; kriteria dan metode penilaian untuk sertifikasi awal, perpanjangan dan sertifikasi ulang.

\section{d. Perpanjangan}

Perpanjangan merupakan prosedur revalidasi dari sertifikasi tanpa ujian setiap saat hingga lima tahun setelah lulus dalam ujian awal, tambahan atau sertifikasi ulang. Sebelum periode pertama validitas (5 tahun) habis dan setiap 10 tahun sesudahnya, sertifikasi dapat diperpanjang oleh LSP-BATAN untuk periode lima tahun berikutnya dengan: a) Menyerahkan bukti dokumen sehat badan dan ketajaman penglihatan yang diambil dalam 12 bulan sebelumnya; b) Menyerahkan bukti pemenuhan aktivitas kerja tanpa jeda waktu tidak bekerja dalam metode UTR radiografi; Jika kriteria b) untuk perpanjangan tidak terpenuhi, maka individu harus mengikuti aturan yang sama untuk sertifikasi ulang. Mekanisme perpanjangan sertifikasi harus memenuhi persyaratan sebagai berikut : a) Surat permohonan dari unit kerja/instansi kandidat, yang ditujukan kepada Kepala PSMN selaku Ketua LSP- BATAN; b) Surat Keterangan Berbadan Sehat dari dokter, hasil pemeriksaan ketajaman mata (J1 sesuai SNI ISO-9712) bagi kandidat ujian radiografi; c) Bukti rekaman kerja 5 tahun terakhir selama memegang sertifikasi keahlian sebagaimana diatur dalam instruksi kerja LSP BATAN yang termutakhir; d) Nilai awal ujian kompetensi dan sertifikasi sebagai dasar kompetensi perpanjangan.

Perpanjangan merupakan tanggung jawab pemegang sertifikasi. Dokumen perpanjangan harus diajukan maksimal dalam waktu 6 (enam) bulan sebelum tanggal berakhirnya sertifikasi. Sebagai pengecualian, bahwa perpanjangan dapat dilakukan maksimum 12 bulan dari masa aktif sertifikasi (BATAN, L, 2020).

\section{e. Sertifikasi Ulang}

Sebelum habis setiap periode kedua validitas (setiap 10 tahun), pemegang sertifikasi dapat disertifikasi ulang oleh LSP-BATAN untuk periode baru lima tahun berikutnya, asalkan pemegang sertifikasi dapat memenuhi klausul 2.1.6.1 a) dan memenuhi ketentuan yang berlaku dijelaskan berikut. Sertifikasi ulang menjadi tanggung jawab pemegang sertifikasi. Dokumen sertifikasi ulang harus diajukan maksimal dalam waktu enam bulan sebelum tanggal berakhirnya sertifikasi. Sebagai pengecualian, dan berdasarkan kebijakan LSP-BATAN, sertifikasi ulang dapat dilakukan dalam waktu maksimal 12 bulan setelah tanggal kedaluwarsa. Jika sertifikasi ulang diterapkan setelah lebih dari 12 bulan setelah berakhirnya maka berlaku ujian sertifikasi awal (umum, spesifik, dan praktek), atau berdasarkan kebijakan LSP-BATAN (BATAN, L, 2020).

\section{METODE PENELITIAN}

Dalam penelitian ini menggunakan sumber data primer dan data sekunder. Data primer mencakup data yang diperoleh langsung dari lapangan yang bersumber dari subyek dan obyek penelitian, berupa wawancara dengan parameter validasi yang efektif untuk pemastian aktivitas kerja berkelanjutan tanpa jeda waktu bagi pekerja radiografi dalam memperpanjang masa pemberlakuan sertifikasi maupun dokumen verifikasi aktivitas kerja level 1 para informan/peserta. Sedangkan data sekunder merupakan pendukung dari standar, buku dan jurnal maupun website yang relevan dalam penelitian ini. Subyek dalam penelitian ini adalah informan berupa peserta perpanjangan sertifikasi UTR untuk metode uji radiografi Level 1 berasal dari industri pengguna radiografi seperti PT. A (informan 1 dan 2), PT. B, (informan 3,4 dan 5), PT. C (informan 6 dan 7) dan PT. D (informan 8 dan 9) yang mendaftarkan diri ke LSP BATAN.

Pada penelitian kualitatif, pengumpulan data secara alamiah (natural setting) dilakukan melalui wawancara, observasi maupun dari studi literatur. Purposive sampling menjadi metode pemilihan sampel yang digunakan pada analisis kualitatif yang dilakukan dengan tujuan tertentu berdasarkan karakteristik/informan yang telah ditentukan (Amarulla, 2020). Pengumpulan data 
yang dilakukan pada penelitian ini melalui wawancara mendalam secara semi-struktur dengan menggunakan panduan wawancara secara langsung dengan informan sehingga diperoleh data-data primer menyangkut parameter keefektifan hasil validasi perpanjangan sertifikasi pemegang sertifikasi UTR.

Analisis data kualitatif sifatnya induktif yakni analisis dengan data yang didapat dikembangkan menjadi hipotesis menuju teori yang dihasilkan. Teknik analisis data menggunakan analisis miles and hubermann meliputi tahapan pengumpulan data, reduksi data, penyajian data, verifikasi data, sebagai berikut: a) Pengumpulan Data (Data Collection); Pengumpulan data dilakukan sejak masa awal penelitian hingga akhir penelitian berupa data primer maupun sekunder. b) Reduksi Data (Data Reduction); Pereduksian data untuk meringkas, memilih data yang dianggap penting sehingga diperoleh informasi yang lebih spesifik dari yang diperoleh c) Penyajian Data (Data Display); Penyajian data berupa uraian singkat yang tersusun sistematis dari hasil data-data yang telah direduksi d) Verifikasi Data (Conclusion Drawing); Penarikan kesimpulan melalui verifikasi data berupa temuan akhir hasil data yang telah diproses (Sugiyono, 2012).

\section{HASIL DAN PEMBAHASAN}

Dalam proses penerapan SNI ISO 9712:2014 melalui sertifikasi perpanjangan, efektifitas memiliki peranan penting agar terlaksananya kesesuaian kompetensi personil yang bekerja dan bertanggungjawab dalam proses pengujian. Pengukuran efektifitas dengan membandingkan hasil antara verifikasi dokumen laporan aktivitas kerja personil UTR selama 5 tahun tanpa jeda waktu tidak bekerja melalui dokumen tertulis saja dengan perbandingannya melalui tambahan validasi wawancara. Perbandingan verifikasi dokumen laporan aktivitas kerja personil perpanjangan sertifikasi UTR radiografi level dengan wawancara validasi perpanjangan sertifikasi UTR Radiografi Level 1 tercantum dalam Tabel 1.

Tabel 1 Hasil Perbandingan Verifikasi Dokumen Laporan Aktivitas Kerja Personil Perpanjangan Sertifikasi UTR Radiografi Level dengan Wawancara Validasi Perpanjangan Sertifikasi UTR Radiografi Level 1

\begin{tabular}{|c|c|c|c|c|}
\hline \multirow[t]{2}{*}{ Informan } & \multicolumn{2}{|l|}{ Verifikasi Dokumen } & \multicolumn{2}{|c|}{ Validasi Wawancara } \\
\hline & $\begin{array}{l}\text { Pemenuhan aktivitas } \\
\text { kerja } \\
\text { Tanpa jeda waktu tidak } \\
\text { Bekerja dan sifat waktu } \\
\text { tidak bekerja }\end{array}$ & Saran & Rata-Rata & Saran \\
\hline 1 & Ya, Tidak kontinyu & $\begin{array}{l}\text { Sertifikasi } \\
\text { perpanjangan }\end{array}$ & 60 & Sertifikasi ulang \\
\hline 2 & Ya, Tidak kontinyu & $\begin{array}{l}\text { Sertifikasi } \\
\text { perpanjangan }\end{array}$ & 60 & Sertifikasi ulang \\
\hline 3 & Ya, Kontinyu & $\begin{array}{l}\text { Sertifikasi } \\
\text { perpanjangan }\end{array}$ & 77,14 & $\begin{array}{l}\text { Sertifikasi } \\
\text { perpanjangan }\end{array}$ \\
\hline 4 & Ya, Kontinyu & $\begin{array}{l}\text { Sertifikasi } \\
\text { perpanjangan }\end{array}$ & 80 & $\begin{array}{l}\text { Sertifikasi } \\
\text { perpanjangan }\end{array}$ \\
\hline 5 & Ya, Tidak kontinyu & $\begin{array}{l}\text { Sertifikasi } \\
\text { perpanjangan }\end{array}$ & 57,14 & Sertifikasi ulang \\
\hline 6 & Ya, Tidak kontinyu & $\begin{array}{l}\text { Sertifikasi } \\
\text { perpanjangan }\end{array}$ & 51,42 & Sertifikasi ulang \\
\hline 7 & Ya, Kontinyu & $\begin{array}{l}\text { Sertifikasi } \\
\text { perpanjangan }\end{array}$ & 74,28 & $\begin{array}{l}\text { Sertifikasi } \\
\text { perpanjangan }\end{array}$ \\
\hline 8 & Ya, Kontinyu & $\begin{array}{l}\text { Sertifikasi } \\
\text { perpanjangan }\end{array}$ & 74,28 & $\begin{array}{l}\text { Sertifikasi } \\
\text { perpanjangan }\end{array}$ \\
\hline 9 & Ya, Tidak kontinyu & $\begin{array}{l}\text { Sertifikasi } \\
\text { perpanjangan }\end{array}$ & 54,28 & Sertifikasi ulang \\
\hline
\end{tabular}

Berdasarkan Tabel 1 diperoleh informasi bahwa ke-9 informan peserta/personil memiliki pemenuhan aktivitas kerja tanpa jeda waktu tidak bekerja, meskipun secara sifat waktu jeda tidak 
bekerja ada yang bersifat kontinyu dan tidak kontinyu. Secara verifikasi dokumen, semua peserta bisa melakukan sertifikasi perpanjangan, namun belum dapat dipastikan secara lengkap informasi bahwa personil tersebut telah bekerja tanpa jeda waktu bekerja dan kompetensinya masih terjaga dan terpelihara sebab masih adanya sifat waktu jeda tidak bekerja yang bersifat tidak kontinyu sehingga keefektifannya baru mencapai $50 \%$ saja. Karenanya membutuhkan validasi kelengkapan data personil melalui wawancara dari hasil verifikasi dokumen laporan aktivitas kerja agar dapat memastikan kompetensi personil masih terjaga dan terpelihara berdasarkan parameter validasi serta memutuskan personil yang bersangkutan dapat memperoleh sertifikasi perpanjangan atau mengikuti sertifikasi ulang.

Kegiatan wawancara pada 9 (Sembilan) informan penelitian menghasilkan data yang tercantum dalam Gambar 1 untuk hasil wawancara terhadap Tujuh parameter validasi.

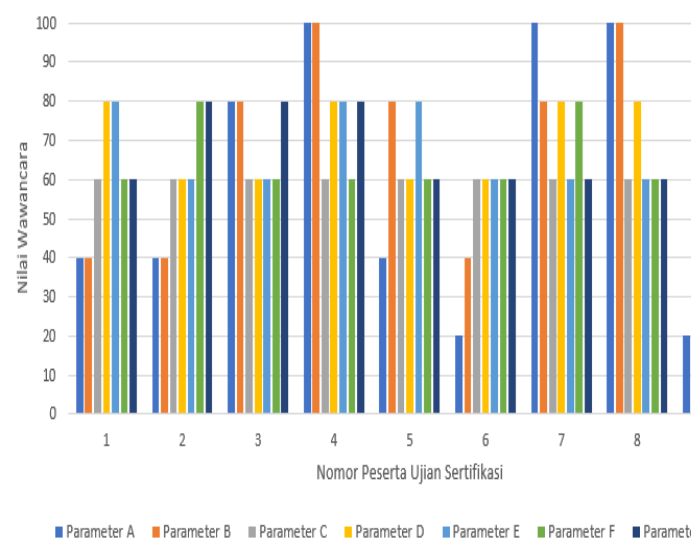

Gambar 1. Hasil Wawancara Peserta sebagai Informan terhadap Tujuh Parameter Informasi tervalidasi

Parameter validasi utama terdiri dari: parameter A yakni kesesuaian penjelasan lisan terhadap pengisian dokumen dan parameter B yakni kesesuaian penjelasan item kegiatan terhadap pengisian dokumen dan pendukung. Khusus untuk parameter utama ini yang harus dipenuhi oleh peserta dengan jelas dan rinci. Nilai parameter utama memiliki bobot lebih tinggi, yakni peserta wajib tidak boleh memperoleh nilai di bawah 70. Jika memperoleh nilai di bawah 70, maka dipastikan saran rekomendasi peserta untuk mengikuti sertifikasi ulang, meskipun nilai parameter pendukungnya lebih tinggi dari 70 . Sedangkan parameter validasi pendukung terdiri dari parameter $\mathrm{C}$, yakni kesesuaian penjelasan infrastruktur dalam melakukan kegiatan UTR Radiografi, Parameter D, yakni kesesuaian penjelasan obyek yang diperiksa dengan UTR Radiografi Parameter E, yakni kesesuaian penjelasan teknik/metoda yang digunakan dalam Uji Tak Rusak Radiografi, Parameter F, yakni Kesesuaian penjelasan informasi terdokumentasi dalam UTR Radiografi serta Parameter G, yakni kesesuaian penjelasan status kualifikasi pekerja terhadap pekerjaan yang ditangani. Parameter pendukung merupakan parameter yang harus dipenuhi dan dijawab peserta sebagai pendukung dari jawaban parameter utama.

Ketujuh parameter tersebut memiliki range Nilai 1-100 dengan standar perpanjangan minimal rata-rata 70 (total gabungan parameter utama (wajib minimal 70) dan pendukung). Jika nilai parameter utama dan total gabungannya di bawah rata-rata 70 , maka saran rekomendasi untuk dilakukan sertifikasi ulang, begitupun sebaliknya jika di atas rata-rata 70 maka direkomendasikan untuk sertifikasi perpanjangan. Berdasarkan hasil wawancara informan yang menjadi peserta perpanjangan sertifikasi UTR untuk metode uji radiografi Level 1 , diperoleh hasil bahwa informan $1,2,5,6$ dan 9 direkomendasikan untuk mengikuti sertifikasi ulang karena range nilai yang dimiliki baik parameter utama dan nilai rata-rata gabungannya di bawah 70 maka disarankan mengikuti sertifikasi ulang terlebih dahulu baru memperoleh sertifikasi perpanjangan. Sedangkan informan 3,4, 7 dan 8 sudah memiliki minimal nilai 70 untuk parameter utama dan gabungan keduanya ratarata 70 sehingga menjadi saran rekomendasi diperolehnya sertifikasi perpanjangan. Oleh karenanya, upaya peningkatan keefektifan penerapan metode SNI ISO 9712:2014 tidak cukup dengan verifikasi dokumen saja namun juga membutuhkan metode validasi melalui wawancara langsung pada peserta perpanjangan sertifikasi UTR radiografi Level 1, karena dapat meyakinkan kepastian aktifitas kerja berkelanjutan yang memuaskan tanpa jeda waktu tidak bekerja dengan informasi lengkap secara utuh dari parameter validasi utama dan pendukung.

\section{KESIMPULAN}

Dengan demikian, penerapan SNI ISO 9712:2014 dapat lebih efektif melalui metode validasi wawancara dengan parameter utama (A dan $B$ ) serta parameter pendukung ( $C, D, E, F$ dan $G$ ) yang mempertegas kebenaran bahwa personil pemegang sertifikat telah bekerja tanpa jeda waktu bekerja dan kompetensinya terjaga yang dikualifikasikan berhak memperoleh perpanjangan sertifikat karena nilai rata-rata parameter utama dan total gabungannya di atas 
70 sebagaimana yang terjadi pada informan 3,4 , 7 dan 8 , sedangkan informan 1,2,5,6, dan 9 memperoleh rekomendasi sertifikasi ulang karena nilai rata-ratanya di bawah 70 , meskipun secara verifikasi dokumen telah memenuhi persyaratan pemenuhan aktivitas kerja tanpa jeda waktu tidak bekerja

\section{UCAPAN TERIMA KASIH}

1. Segenap pegawai Bidang Pengembangan Standar (BPS), Bidang Jaminan Mutu (BJM) dan Bidang Akreditasi dan Sertifikasi (BAS) Pusat Standardisasi dan Mutu Nuklir (PSMN) yang mengelola tugas dan fungsi unit kerjanya dalam kegiatan sertifikasi person bidang ketenaganukliran, membentuk lembaga sertifikasi person bidang uji tak rusak melalui Lembaga Sertifikasi Person BATAN

2. Para peserta perpanjangan sertifikasi UTR Level 1 yang terdiri dari PT. A (informan 1 dan 2), PT. B, (informan 3,4 dan 5), PT. C (informan 6 dan 7) dan PT. D (informan 8 dan 9) yang mendaftarkan diri ke LSP BATAN

\section{DAFTAR PUSTAKA}

Amarulla, O. (2020) Metodologi Penelitian Kuantitatif: Sampling dan Teknik Analisis Data. Bogor: Universitas Pertahanan.

BAPETEN. (2013). Peraturan Kepala Badan Pengawas Tenaga Nuklir Nomor 4 Tahun 2013 tentang Proteksi dan Keselamatan Radiasi Pengion dalam Pemanfaatan Tenaga Nuklir. [Regulation of the head of the Nuclear Energy Regulatory Agency No. 4 of 2013 concerning Protection and Safety of lonizing Radiation in Nuclear Power Utilization].

BAPETEN (2014) Peraturan Kepala Badan Pengawas Tenaga Nuklir Nomor 16 Tahun 2014 tentang Surat Izin Bekerja Petugas Tertentu yang Bekerja di Instalasi yang Memanfaatkan Sumber Radiasi Pengion. [Regulation of the head of the Nuclear Energy Regulatory Agency Number 16 of 2014 concerning Work Permits for Certain Officers Working in Installations that Utilize Ionizing Radiation Sources].

BATAN, L. (2020) Skema Sertifikasi UTR. Tangerang Selatan: BATAN.

BATAN, L. (2020) Prosedur Sertifikasi Person. Tangerang Selatan: BATAN
BATAN, L. (LSP) (2020) Pedoman Mutu. Tangerang Selatan: BATAN.

BSN (2014) Uji tak rusak - Kualifikasi dan sertifikasi personel. Tangerang Selatan: BATAN.

BSN. (2012). SNI ISO/IEC 17024: 2012. Penilaian Kesesuaian - Persyaratan Umum Lembaga Sertifikasi Person. [Conformity assessment - General requirements for bodies operating certification of persons].

Crane, Robert L. (2018). Radiographic Inspection of Composite Materials. Comprehensive Composite Materials II, Volume 7, pages 167-194.

KAN. Direktori Klien LSP. [LSP Clients Directory]. Retrieved July 8, 2020 from http://www.kan.or.id/index.php/document s/terakreditasi/doc17021/sni-isoiec17024/lembaga-sertifikasi-person LSP BATAN. (2018a).

Kumaraningrum, A. R. (2019) 'EVALUASI KINERJA PERSON TERSERTIFIKASI BIDANG UJI TAK RUSAK UNTUK MENDUKUNG PENERAPAN SNI / ISO IEC 17024: 2012 DI LEMBAGA SERTIFIKASI PERSON BATAN Evaluation on Performance Certified Person of NonDestructive Testing Fields to Support the Implementation', Prosiding PPIS BSN, 1, pp. 219-228.Munawar, Yusuf. (2018). Manfaat Berganda dari LSP - Lembaga Sertifikasi Person yang Terakreditasi SNI ISO/IEC 17024. [Multiple Benefits of LSP _ Person Certification Bodies who are SNI ISO / IEC 17024 Accredited]. Retrieved July $8, \quad 2019$ from http://lspmks.co.id/2018/07/23/manfaatber ganda-dari-lsp-lembaga-sertifikasipersonyang-terakreditas-sni-iso-iec17024/

Podgorsak, E. B. (2005). Radiation oncology physics. Vienna: International Atomic Energy Agency, 123-271.

Rahman, F. (2012) Sekilas Tentang NDT. Jakarta: Universitas Mercu Buana.

Soembogo, D. (2016). Radiografi sinar-X pada coran bracket. [X-ray radiography on castings bracket]. Seminar Nasional Pendayagunaan Teknologi Nuklir, 1, 134140.

Sugiyono (2012) Metode Penelitian Kombinasi (Mix Method). Bandung: BATAN. 
Sutanto, Jepri, dkk. (2018). Kajian Penerapan Standar Iptek Nuklir ISO 9712 Bidang Uji Tak Rusak (UTR). [Study of the Implementation of Nuclear Science and
Technology Standards ISO 9712 NonDestructive Testing (NDT)]. Prosiding PPIS 2018, pp. $83-89$ 